NOTAS

\title{
LA MAGIA DEL ARTE HAITIANO Nadège Dutardre*
}

\section{$\mathbf{E}_{\text {n }}$} generaciones de pintores que, desde hace casi un siglo, sorprenden al mundo con la magia de sus creaciones. Esta tierra haitiana, esta "Kiskeya" de los indios Tainos, es hoy la Haití de la miseria, de la desesperación, de la sangre derramada tantas veces: un país donde la historia parece tener hipo desde hace cerca de dos siglos.

Pero es también la Haití de la grandeza, la primera nación negra independiente, ${ }^{1}$ un pequeño país donde los más grandes superlativos son posibles. La "Haití querida" de los poetas, la Haití del arte, la que el genio de los colores parece haber escogido para establecer su domicilio.

¿Por qué aquí más que en otro lado? ¿Por qué esta república del Caribe es la única en el mundo negro que

- Doctora en Sociología de la Universidad de París. Traducción de Silvia Pasternac.

${ }^{1}$ Haití debe celebrar en una docena de años el bicentenario de su independencia. alcanzó un grado semejante de riqueza en el arte pictórico?

En efecto, ni en el África ancestral ni en las repúblicas del nuevo mundo, hubo otro pueblo negro que haya podido desarrollar semejante grado de consumación en esta forma de arte.

Claro está que fue necesario un elemento catalizador; la pintura en este país no nació de manera totalmente espontánea. El arte existía en estado bruto antes de la explosión de los pintores haitianos; se expresaba a través de los objetos habituales, de los anuncios, de las fachadas de los pequeños tenderetes, de los camiones públicos, sobre los cuales se pueden ver las reproducciones de escenas biblicas, de imágenes del vudú, de proverbios e inscripciones diversas, que condensan la imaginería popular de su pueblo, de sus preocupaciones y de sus valores.

En 1944, mientras Europa vivía las horas inás amargas de su historia, y la aventura del surrealismo se continuaba sobre el continente americano, a 
NOTAS

algunos miles de kilómetros, en Haití, un norteamericano, De Witt Peters, daba un primer impulso a la pintura "ingenua", al crear el Centro de Arte Haitiano, en Port-au-Prince.

En ese entonces, el mundo ignoraba todo sobre la exhuberancia de un arte que encontraría, algunos años más tarde, su lugar en las más grandes galerías y museos del mundo.

Este será el verdadero nacimiento de la pintura haitiana. Al crear el Centro de Arte, De Witt Peters le dio a esta pintura paralelamente un público a través de sus compradores, principalmente norteamericanos.

Antes de la llegada de De Witt Peters a la isla, pocos pintores eran distinguidos como tales. Este conocedor ilustrado, entusiasmado por "la exhuberancia primitiva" de algunos pintores autodidactas, decidirá estimular lo que entonces no era más que un pasatiempo para estos pintores aficionados. El Centro responderá rápidamente a una demanda comercial. Por suerte, esta pintura espontánea pudo escapar de una empresa a gran escala, y si bien puede haber estado enferma de turismo, no murió a causa de él. Trastornado por las vicisitudes de la historia nacional, el flujo de turistas norteamericanos se hizo cada vez más escaso, y el genio creativo haitiano pudo escapar, de este modo, de una sobre-explotación amenazante.

En el seno de esta prolífica empresa figuraron auténticos artistas con talento espontáneo, que son citados sinxe- sar entre los mejores y los más admirados de los pintores "ingenuos" sobre la escena internacional. Sea cual sea el nombre que se le haya podido dar a este movimiento, "ingenuo", "popular" o "primitivo", su orientación apuntaba entonces a dar forma a ese inconsciente colectivo del pueblo haitiano, a sus componentes, sus orígenes, sus creencias, su apego constante a la "Guinea" y al "Dahomey" míticos. ${ }^{3}$

La mayoría de las pinturas de esa época están cargadas, en efecto, con simbolismos. En sus composiciones se mezclan numerosas evocaciones de las prácticas rituales y mágico-religiosas, y se mueven una multitud de criaturas místicas: los "loas" o los santos del panteón vudú, criaturas bien vivas de la cotidianeidad haitiana.

En este derroche de colores no hay respeto de la "profundidad de campo" o de la perspectiva, tal como podrían estar dictadas por la formación tradicional. Es la pintura del instinto y del instante, donde coexisten la huella de lo sagrado y el sentido del más mínimo detalle del mundo circundante.

${ }^{2}$ Los esclavos eran originarios de la costa oeste de Africa, que en aquella época se llamaba Costa de Guinea.

${ }^{3}$ El vudú haitiano mezcla elementos tomados del catolicismo con la sobrevivencia de religiones africanas, principalmente originarias del ex Dahomey, en lo que concierne a Haití. 
NOTAS

Alfred Métraux ${ }^{4}$ afirmaba en 1958 "que en el campo de la expresión artística de Haití, el papel del vudú es innegable"; hablaba entonces de la música y de la danza, pero podemos, sin ninguna duda, agregar que la pintura sufre también sus influencias destacadas.

La religión y la referencia a los espíritus y dioses del vudú son omnipresentes en la vida cotidiana y se manifiestan de mil maneras.

Comprendemos entonces por qué el apego a lo irracional y a lo sagrado está tan bien transcrito por los pintores "ingenuos".

Lo que caracteriza a esa pintura es, por supuesto, la evocación frecuente de los temas religiosos, pero también la atractiva frescura y la riqueza de su percepción, ya sea que se trate de la transcripción de lo real o de la transcripción de un mundo imaginario. Una última característica, finalmente, es la nota poética que emana casi siempre de sus cuadros. Todos los observadores han podido notar la frescura de la pintura ingenua haitiana, así como la ausencia de escenas trágicas. Las escenas son generalmente gozosas y los sujetos están cargados de alegría comunicativa.

iPara combatir la alienación interior y la contaminación exterior, cuando todo se vuelve súbitamente

\footnotetext{
${ }^{4}$ A. Métraux; La vaudou Haïtien (Elvudú haitiano).
}

\begin{abstract}
desalentador, sucio y gris, no hay verdaderamente mejor remedio que esos cuadros que nos traen tanto sol y tanto azul! 5
\end{abstract}

\section{EI segundo aliento de la pintura hai- tiana}

La pintura haitiana encontrará muy rápidamente una nueva mirada y un segundo aliento que marcarán, a partir de ese momento, su entrada en el mundo del arte internacional.

En efecto, en 1945, André Breton, después de un viaje a México, se quedó un tiempo en Haití y en las Antillas francesas. Fue el encuentro del maestro del surrealismo con los pintores espontáneos; el comienzo de una maravillosa aventura para estos magos del color que sólo disponían entonces medios improvisados.

Los pintores casi desconocidos, que André Breton descubrirá, no tenían ninguna formación artística, pero la riqueza de sus creaciones les dará rápidamente una reputación que traspasará las fronteras de la república.

Sin ningún dominio de las reglas académicas o de una didáctica convencional, nacieron algunos grandes talentos:

\footnotetext{
${ }^{5}$ A. Jokovsky, Peintres natifs (Pintores nativos).
} 
NOTAS

Philomé OBIN; ${ }^{6}$ hijo de sastre, ejerció distintos oficios (peluquero, comerciante de café...) antes de dedicarse a la pintura. Está considerado como uno de los maestros del arte haitiano. Es el pintor de las multitudes, de las fiestas, de los acontecimientos históricos. "Las cuatro víctimas inocentes", "La fiesta escolar", "Los burgueses del Cabo Haitíano hacia 1900", se cuentan entre sus composiciones principales.

Hector HYPPOLITE; el más grande y conocido de los pintores "ingenuos" haitianos. Muchos de sus cuadros están extraídos de la mitología vudú: "La mambo", "Amante Aizan", "Los zombis". Este universo era familiar y debía ser, para él, una fuente importante de inspiración. Hector Hyppolite era "houngan" (sacerdote del culto vudú) y representará muchas escenas místicas.

Según André Breton, "se trata de las primeras representaciones que se hayan dado de las divinidades y de las escenas vudú en Haitî".

Entre sus obras hay numerosas composiciones de carácter simbolista, como "Sueño de un angel", así como paisajes y retratos: "Nube y pájaros", "Mujer en el salón", "Retrato del artista"...

${ }^{6}$ Philomé OBIN (nacidoen 1891); Hector HYPPOLITE (1894-1948); Preféte DAFFAUT (nacido en 1923); Wilson BIGAUD (nacido en 1931).
Con Préfète DUFFAUT, es el mundo de lo sobrenatural el que cobra vida en sus lienzos, hechos a imagen y semejanza de sus sueños. Es uno de los pintores más admirados hoy. Semejantes a su ciudad natal, sus lienzos nos recuerdan cuentos para niños donde lo maravilloso y lo mágico están presentes: amontonamientos de casitas de mil colores, caminos que serpentean en el firmamento y multitudes coloridas que cobran vida dentro de una geografía laberíntica.

La figuración de este mundo tan elaborado es animada (como en el caso de los pintores anteriores) por las creencias mágicas. Por eso, no debe sorprender encontrar entre sus obras títulos como "Sueño místico" o "Escenas vudú".

Incluyamos además, entre estos artistas del instinto a Wilson BIGAUD; quien compuso una de las obras más hermosas del arte "ingenuo" haitiano: "El paraiso terrestre". Se trata de una representación admirable del pecado original; una descripción apacible y gozosa del paraíso transportado al corazón de la selva tropical haitiana, donde Adán y Eva se mueven dentro de un universo ideal e ingenuo de brillantes colores.

Dichos pintores se cuentan entre los más conocidos y los más frecuentemente citados, pero sólo se trata de una breve ojeada, casi sacrílega, de la pintura haitiana. Son centenares los pintores haitianos-talentos conocidos $\mathrm{u}$ otros no $\tan$ conocidos-que ejercen 
su arte en la isla, pero también en Europa, sobre el continente norteamericano, o en algún lugar entre las islas vecinas del Caribe.

\section{El surrealismo y los pintores "inge- nuos"}

Por la espontaneidad de su percepción y la frescura de sus composiciones, los primeros pintores "ingenuos" haitianos provocaron curiosidad muy rápidamente, y se atrayeron la simpatía. La simpatía de los más grandes, como Breton en 1945, cuya visita conducirá a un acercamiento sorprendente entre los surrealistas y los pintores "ingenuos" haitianos.

¿Por qué misteriosa alquimia se iban a encontrar estas dos corrientes?

El surrealismo, movimiento literario y también artístico -quiza el más grande de este siglo- estaba conducido por una actitud intelectual que predicaba el trastocamiento de los valores en ese medio. Trastocamiento que debía realizarse por la liberación del espíritu a través de diversas experiencias y a través de la prospección del mundo del sueño y del inconsciente.

Este movimiento tuvo el mérito de suprimir el aislamiento de las diferentes formas del arte y permitió el encuentro, el entrecruzamiento de las artes primitivas, de las artes populares o ingenuas, de la pintura académica, pero también de los objetos más habi- tuales y de las creaciones $\mathrm{u}$ objetos alienados...

Los pintores surrealistas que pintaban el universo del sueño y del inconsciente, liberados de las exigencias y de los límites impuestos por la tradición clásica, sin duda alguna no podían perderse del encuentro con los pintores "ingenuos" haitianos, que pintaban, a su manera, sus sueños; en una explosión de colores, de formas, de apariciones extrañas, tan llenas de inventiva.

Para los surrealistas que expresaban su universo interior, era necesario favorecer la fusión de lo real y de lo imaginario. El universo onírico y la búsqueda de estados psicológicos profundos suprimen la censura dictada por el razonamiento conciente $y$, de este modo, "el espíritu del hombre que sueña se satisface plenamente con lo que le ocurre. La angustiante cuestión de la posibilidad ya no se plantea". ${ }^{7}$ El sueño ofrece los elementos que estarán estructurados y a los que se dará forma para revelar y dar vida a su contenido bajo la forma de imágenes. Una de las originalidades del surrealismo consiste en haber dado al sueño ese poder creador, desde un punto de vista del arte.

Con el sueño y las manifestaciones libres de la imaginación, desembarazada del espíritu crítico, las creaciones revisten un carácter surrealista. Así,

${ }^{7}$ A. Breton, Manifestes du surréalisme (Manifiestos del surrealismo). 
NOTAS

Joan Miró, que se abandonará totalmente al "automatismo", será calificado por André Breton como el más grande de los surrealistas.

André Breton consideraba que en la sociedad actual, "la realidad interior y la realidad exterior estaban en contradicción" y se dedicó, con los surrealistas, a "cuestionar en cualquier ocasión estas dos realidades en presencia, al rechazar la prevalencia de una sobre la otra". 8

Para algunos pintores "ingenuos" haitianos, el encuentro de estas dos realidades y la ósmosis misma parecen estar actuando constantemente. La inspiración viene a veces del exterior, y se trata entonces de la transcripción cándida de las escenas cotidianas 0 , por el contrario, la inspiración viene de lo más profundo de ellos mismos, entonces las apariciones son fugitivas, intangibles, y una gran fantasía parece manifestarse en los colores y en las formas.

El poder creador y la sorprendente fuente de inspiración que tienen se explican a veces con la presencia de lo sobrenatural. En otros casos ya no es el artista el que está pintando, sino los "loas", que hablan, que pintan y que se transforman en genios del color. Porque, en efecto, es el atributo de los "loas", de los dioses del vudú, el manifestar su presencia, el habitar el cuerpo de sus "elegidos".

${ }^{8}$ A. Breton, Qu'est-ce que le surréalisme? (¿Qué es el surrealismo?)
Incluso, si no pintan en estado de trance, se dejan llevar totalmente por su inspiración, dictada de mil maneras, sin una inhibición causada por el espíritu crítico, libres de toda traba.

De los lienzos brota un universo encantado, un universo fantástico y se ven fusionados así, como por milagro, el universo de lo cotidiano y el universo de lo asombroso. Y "lo asombroso es siempre bello; cualquier cosa asombrosa es bella; incluso, sólo lo asombroso es bello".

\section{Encuentro entre un surrealista y la mágica Haití}

Haití no fue, claro está, el único país negro que ofreciera una fuente de inspiración a los pintores innovadores de este siglo. Antes de los surrealistas, los cubistas ya habían sido seducidos por el arte africano y varias de sus obras están claramente marcadas por esta inspiración. Al "geometrizar" y reducir las formas de los volúmenes, se podía ver cómo los rostros se mostraban de frente y de perfil al mismo tiempo; en algunas de estas obras el resultado era a veces muy cercano al de la plástica de la máscara africana.

Más tarde, el arte del mundo negro atraerá igualmente a los surrealistas, y la mágica Haití fascinará a su vez a numerosos pintores de este movimien-

\footnotetext{
${ }^{9}$ A. Breton, Manifestes du surréalisme (Manifiestos del surrealismo).
} 
to. Contrariamente al arte escultórico africano, que poseía una función social, la pintura haitiana sólo era gozo sensual, dotada con un poder tan atractivo y magnético que no podía dejar indiferentes a pintores como los surrealistas.

Un pintor en particular mostrará sumo interés por este país y por sus pintores: Wifredo Lam, ${ }^{10}$ de origen cubano, que será apoyado en París por Picasso y que obtendrá rápidamente una fama internacional.

Este acercamiento no fue provocado, por supuesto, por la proximidad geográfica de los dos países (por otro lado, Lam vivía en Europa), sino por la herencia cultural africana que les era común, y de donde él tomó su inspiración. En el retorno a las fuentes y a esta herencia se encuentra el origen de un viraje decisivo dentro de su obra, mismo que provocará el inicio, paralelamente, de la celebridad de algunos pintores "ingenuos" haitianos, como Hector Hyppolite, quien observó, comprendió, amó la vida del pueblo haitiano y transportó numerosas representaciones de las divinidades salidas del panteón vudú dentro de sus composiciones.

Sin duda, Lam debe ser considerado como aparte dentro del movimiento surrealista; porque incluso si bien tiene en común con este movimiento un rechazo del academicismo, no tomará su inspiración del universo del

${ }^{10}$ Wifredo Lam (1902-1982). sueño, sino de un universo familiar y muy real: el del Caribe; se abastecerá y se realizará principalmente gracias a los renovados contactos con el universo mágico-religioso de los ritos heredados del África ancestral.

En 1946, se queda durante algunos meses en Haití, donde asiste a ceremonias vudá; ceremonias donde se mezclan ritos de origen africano y prácticas católicas, durante las que "los espíritus se manifiestan en personas a las cuales les prestan sus rasgos y sus gestos familiares". ${ }^{11}$ Observará igualmente unos "vevés", dibujos emblemáticos con carácter mágico, que tienen como función llamar a los "loas" y obligarlos a manifestarse. Podemos leer en esos "vevés" los atributos característicos de los "loas": el sable de Ogou, el barco de Agoué, la serpiente de Damballah..., atributos que reencontramos en numerosos cuadros.

Esa experiencia lo marcará definitivamente y de tal encuentro nacerá un nuevo estilo, donde la referencia a los dioses de la mitología vudú es muy clara. "Ogoun ferraille", "Altar para Yamaya", "Los Abaloches bailan para Dhamballa, dios de la unidad", se cuentan entre sus obras más conocidas de este período fecundo. Del encuentro entre Wifredo Lam y el pueblo de Haití, André Breton escribió en 1946, en Port-au-Prince, un texto que sigue

\footnotetext{
${ }^{11}$ A. Metraux; Le vaudou Haîtien (Elvudú haitiano).
} 
NOTAS

siendo célebre, un himno al artista y a la mágica Haití: ${ }^{12}$

Por la noche, en Haití, las hadas negras sucesivas llevan a siete centímetros por encima de los ojos las piraguas de Zambeze, los fuegos sincrónicos de los niños, los campanarios dominados por un combate de gallos y los sueños de Eden que se sacuden enfrentados alrededor de la desintegración atómica. A sus pies, Wifredo Lam instala su "vever", es decir, el maravilloso y siempre cambiante resplandor que viene de los vitrales increiblemente labrados por la naturaleza tropical sobre un espíritu liberado de cualquier influencia y predestinado a hacer que surjan, de este resplandor, las imágenes de los dioses.

Esta rápida incursión en el universo de la surrealidad puede dejarnos una sensación desconcertante; se nos abre un mundo de ideas vagas, que son difíciles de codificar según los criterios habituales que cada uno posee sobre el esteticismo. En efecto, la complejidad de las formas y la asociación de imagenes dispares vuelve ardua, para nuestro espíritu de neófitos imbuidos de racionalidad, la lectura de la obra de arte.

${ }^{12}$ A. Breton, Le surréalisme et la peinture (El surrealismo y la pintura).
El arte "ingenuo", por su parte, ofrece unas imágenes perfectamente inteligibles y otras teñidas de misticismo y de sobrenatural, que vuelven difícil su desciframiento. ¿Qué más da el enigma insoluble? iLa obra existe!

¿Y acaso no es mejor dejar de lado el cuestionamiento, dejarse llevar por esta surrealidad que nos sobrepasa; hacer como sus creadores, dejar que se exprese lo imaginario fuera de la censura de la razón, así como los sentimientos y la emoción que nos susci$\tan$ las formas y los colores que saltan del lienzo?

\section{Pintores "ingenuos" y nuevas corrien-} tes

Ciertamente, las imágenes que evocamos frente a palabras como pintura haitiana son casi esencialmente las de la pintura ingenua, ese himno a la libre imaginación y a la fantasía.Pero si bien los artistas de esta corriente son sin duda los más conocidos, no deben hacernos olvidar la multitud de vocaciones que ellos hicieron nacer. Haití es uno de los raros países subdesarrollados que ha dado tantos artistas en un período tan corto; "el único pueblo de pintores", según André Malraux. ${ }^{13}$

La emulación que nació de este período fecundo permitió que se expresaran otras corrientes; se multi-

\footnotetext{
${ }^{13}$ A. Malraux, L'intemporel (Lo intemporal).
} 
plicaron los intentos y, paralelamente a los "ingenuos", numerosos talentos se revelaron, esta vez sobre caminos distintos, surrealistas, claro está, impresionistas y otros estilos más, dentro y fuera del país.

Estas son trayectorias sorprendentes para unos pintores que a veces están desconectados con sus raíces originales. El viaje al corazón del arte haitiano nos lleva a descubrir o a redescubrir, por ejemplo, el itinerario singular de un joven artista, Jean-Michel Basquiat, ${ }^{14}$ sin formación artística, pintor del instinto, como los "ingenuos", amigo de Andy Warhol, con el que pintó numerosos lienzos en los años ochenta. Fue conocido primero por sus famosos graffitis en el metro de Nueva York (extraño mundo del graffiti que interesó igualmente a los surrealistas -ellos otra vez- por los valores que vehiculizaba), atraerá rápidamente la atención por sus cuadros y se pondrá de moda rápidamente en los medios no expresionistas. Despreciado por la crítica de su época e incomprendido durante su vida, hoy es celebrado con regularidad, y algunos de sus lienzos alcanzan precios elevados, como "Famous Moon King".

Según Victor Bockris, ${ }^{15}$ sus cuadros eran combinaciones delirantes de dibujos muy crudos, signos misteriosos garabateados y "mensajes". Eran, sin duda, mensajes de rebelión, tratán-

\footnotetext{
${ }^{14}$ Jean-Michel Basquiat (1960-1988).

${ }^{15}$ V. Bockris, Andy Warhol.
}

dose de un pintor de la minoría étnica de Nueva York, que pintaba con toda su fragilidad y sus esperanzas, la calle, la violencia, mezcladas con elementos tomados de la herencia cultural caribeña.

\section{El devenir de la pintura haitiana}

La voluntad de analizar la obra de arte, particularmente la obra ingenua, por su raíz, nos llevó a explicar, a reflexionar sobre las condiciones de su producción y sobre su pasado, pero ¿qué podemos decir sobre su evolución y su devenir?

Esta pintura, que fue revelada al mundo hace casi un siglo, ha evolucionado; algunos artistas, confrontados con el mundo moderno, cambiaron sus estilos y las fuentes de inspiración a veces, se agotaron, provocando que sus creaciones se volvieran insípidas o inexistentes. Otros, en cambio, permanecieron protegidos de los efectos perversos del modernismo.

Pero su arte está hoy muy lejos de encontrarse esclerosado; a imagen y semejanza de su pueblo, está, por el contrario, increiblemente vivo. Su poder creativo y sus posibilidades de expresión son tales que aparecen sin cesar nuevos talentos.

¿Qué podemos decir hoy de la pintura en el país? Sin duda, ESTA VIVA... pero se encuentra frente a dificultades crecientes: los dramas 


\section{NOTAS}

que sacuden a Haití desde hace algunos años han provocado que los visitantes huyan, y con ellos, los admiradores potenciales de este arte.

¿Podemos prever lo que será su futuro? ¿Se encuentra amenazada la fuente misma de esta actividad creativa? Es difícil contestar ... Pero una mirada optimista hacia el pasado nos muestra que siempre ha podido triunfar sobre todas las amenazas y que atravesó la historia con metamorfosis y estallidos, con un dinamismo que se renueva cada vez.

En un nuevo vuelco de su historia, formulemos el deseo de que pueda renacer a la esperanza, que pueda continuar perpetuando el sentido de lo bello, de lo mágico, del sueño, que son los elementos con que ella nos ha maravillado siempre.

\section{Referencias bibligráficas}

Victor Bockris, Andy Warhol, París: Plon,1990.

André Breton, Manifestes du surréalisme (Manifiestos del surrealismo); París: Gallimard, 1989; Le surréalisme et le peinture (El surrealismo y la pintura); París: Gallimard, 1965.

Jean-Marie Drot, Voyage au pays des naïfs (Viaje al país de los ingenuos), París: Hatier, 1986.
P. Gaudibert y J. Leenhardt, Wifredo Lam - Oeurres e Cuba (Wifredo Lam, obras de Cuba), París: Lib. Segurier, maison d'Amérique Latine, 1989.

Madeleine Gravelle, Les peintres naïs - illuminés de l'instinct (Los pintores "ingenuos" - iluminados del instinto), París: Filipacchi, 1977.

Anatole Jakovsky, Peintres naifs (Pintores "ingenuos"), Basilea: Basilius-Press AG, 1976.

(No se indica autor) Peintures haïtiennes (Pinturas haitianas), Delroisse, París: Vilo.

André Malraux, La métamorphose des dieux (La metamorfosis de los dioses), vol. 3, L'Intermporel, Paris: Gallimard, 1976.

Alfred Métraux, Le vaudou Haïtien (El vudú haitiano), París: Gallimard, 1977. 